\title{
Adsorption behavior of organoarsenic species DMA, DMMTA and DMDTA on clay mineral surfaces
}

HYE-ON YOON ${ }^{1 *}$, MINKYU CHO ${ }^{1}$, SU-JEONG KIM ${ }^{1}$, SEULKI JEONG ${ }^{1}$, SANG-MIN PARK ${ }^{2}$, JiNSUNG AN ${ }^{3}$

${ }^{1}$ Korea Basic Science Institute, Seoul 02841

Korea(*correspondence: dunee@kbsi.re.kr)

${ }^{2}$ Geum River Basin Environmental Office, Ministry of

Environment, Korea(sangmin8657@gamil.com)

${ }^{3}$ Department of Biological \& Environmental Engineering,

Semyung University, Korea(jsan@semyung.ac.kr)

Reaction mechanism of organoarsenic species on surfaces

Removal of organoarsenic species by clay minerals, DMA, DMMTA and DMDTA shows strong depenency on $\mathrm{pH}$ as well as different clay surfaces Kaolinite and Montmorillonite.

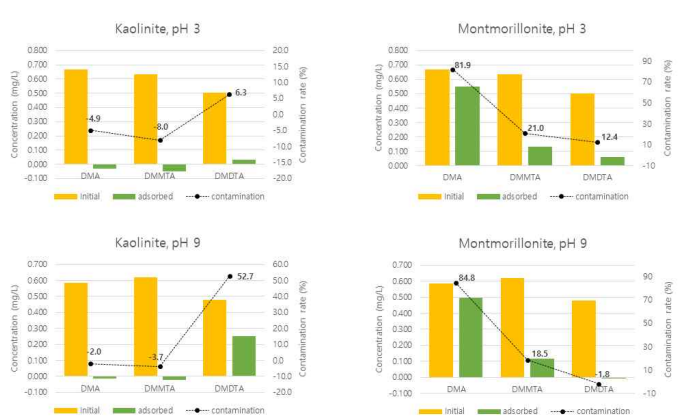

Figure 1. Adsorption experiment of DMMTA and DMDTA on Kaolinite and Montmorillonite at pH 3 and $\mathrm{pH} 9$.

\section{Discussion of Results}

DMA and DMMTA did not appear to be contaminated with Kaolinite at pH 3 and 9, but the possibility of partial contamination of DMDTA at $\mathrm{pH} 9$ was confirmed. In Montmorillonite, DMA had a contamination rate of about $80 \%$ regardless of $\mathrm{pH}$ conditions and a low contamination rate of about $20 \%$ of DMMTA(Fig. 1).

Adsorption behavior of arsenic species at different $\mathrm{pH}$ and solid often control the fate in natural environment $[1,2]$.

Acknowledgement: This research was supported by the National Research Foundation of Korea (grant number NRF2019R1A2C2007092)

[1]Nasrin Ghorbanzadeh et al.(2015) Geosystem Engineering 18. 302-311. [2] Yarong Li et al.(2011) Jr. of Hazardous Materials. 188 140-147. 